\title{
Endophyte Initiation Beauveria bassiana (Balsamo) Vullemin (Hypocreales: Cordycipitaceae) in Reduction of Aphis glycine Matsumura (Hemiptera: Aphididae) Investation in Soybean (Glycine max (L.) Merrill) Plant
}

\author{
Mufidah Afiyanti ${ }^{1}$, Rina Rachmawati ${ }^{2}$, Achmad Faisal Akbar ${ }^{2}$, Rose Novita Sari Handoko ${ }^{1}$, \\ Bambang Tri Rahardjo² \\ ${ }^{1}$ Master Program of Natural Resources Management. Postgraduate School. Universitas Brawijaya, Malang, \\ Indonesia, 65145 \\ ${ }^{2}$ Department of Plant Protection, Faculty of Agriculture, Universitas Brawijaya, Malang, Indonesia, 65145
}

\begin{abstract}
Soybean (Glycine max (L.) Merrill) is a universal important plant. Its production has decreased each year. A major problems is a pest known as Aphis glycine Matsumura (Hemiptera: Aphididae) which caused the decline of yield up to $40 \%$. Thus, there is a need to control $A$. glycine. Recent studies showed B. bassiana has a potency as endophyte in Vicia faba (Fabaceae) plant tissue. It could harm A. gossypii and causes death up to $57,7 \%$. Therefore, the aim of this research is to control infestation of $A$. glycine by using B. bassiana. This research used Randomized Block Design with soybean plant Anjasmoro variety as samples. The initiation of $B$. bassiana was conducted by using seed-soaking and soil-wetting methods. The results showed that fungus $B$. bassiana was able to colonize soybean plants with a percentage of colonization reaching $6.67 \%$. Colonization was only found in the stems of soybean plants in the seed immersion treatment with the susceptibility of $B$. bassiana fungus in density of 108 conidia / $\mathrm{mL}$ for 2 hours, colonization on the stem itself by $20 \%$. Fungus density results from evaluation of $1.6 \times 105$ conidia / mL and conidial viability reached $87.4 \%$. There were no deaths and changes in the population of A. glycine aphids. Direct pathogenicity testing has a significant effect on the treatment between observations of the second day. Initiation of $B$. bassiana fungi did not significantly affect plant height and number of leaf branches. This results conclude that B. bassiana may function as endophyte in soybean plants. However, its function in reduction of greenfly still need further research
\end{abstract}

Keywords: Biological control, Environmental pest management, Greenfly

\section{INTRODUCTION}

Soybean (Glycine max (L.) Merrill) is a plant that has important value as a source of vegetable protein with an average production of the last two years reaching 968,982 tons and experiencing an increase [1]. Production factors that can eliminate the results are Plant Disturbing Organisms (OPT). Aphis glycine Matsumura aphids (Hemiptera: Aphididae) is one of the potential pests of soybean plants that can cause a decrease in yield of more than $40 \%$ [2], so control is needed for these pests. Biological control measures by utilizing natural enemies of pests. One of the natural enemies of $A$. glycine comes from a group of fungi namely Beauveria bassiana (Balsamo) Vullemin (Hypocreales: Cordycipitaceae). Beauveria fungi are cosmopolitan fungi and the range of this fungus host is about 100 species. This fungus also has unique properties which can act as endophytes in plant tissues. The potential of $B$. bassiana fungi as endophytes in the Vicia faba (Fabaceae) plant

Author's Correspondence Address: Mufidah Afiyanti

Email : mufidahafiyanti@gmail.com

Address : Master Program of Natural Resources

Management. Postgraduate School. Universitas Brawijaya tissue can cause death by $57.7 \%$ [3]. The development of $B$. bassiana fungi as endophytes aims to increase the resistance of soybean plants from the attack of $A$. glycine aphids.

\section{MATERIAL AND METHOD}

This study uses Randomized Block Design (RCBD) with 4 treatments and 5 replications, so as to obtain 20 experimental units. The soybean plants used are Anjasmoro varieties. This research is divided into preparation and implementation of research. Preparation of the study included making media, propagating fungus $B$. bassiana, maintaining $A$. glycine aphids, and planting. Research implementation includes fungus initiation, direct pathogenicity testing, endophytic pathogenicity testing, and evaluation.

The implementation of the research included fungal initiation, direct pathogenicity testing, endophytic pathogenicity testing, and evaluation. Analysis of data using analysis of variance, if the treatment shows a significant effect, followed by the LSD test at the error rate of $5 \%$. In fungal initiation, there is formula: 
- Calculation of density

$$
J=\frac{t \times d}{(n \times 0,25)} \times 10^{6}
$$

$\mathrm{J}=$ number of conidia in one $\mathrm{mL}$ of conidia (conidia / $\mathrm{mL}$ )

$\mathrm{t}=$ number of conidia in all square squares calculated

$\mathrm{d}=$ = dilution factor if it must be diluted

$0.25=$ constant

$\mathrm{n} \quad=$ number of boxes calculated (5 large boxes $\times 16$ small boxes)

- Conidia viability calculation

$$
V=\frac{g}{(g+u)} \times 100 \%
$$

$\mathrm{V}=$ percentage of conidia germinating

$\mathrm{g}=$ number of conidia germinating

$\mathrm{u} \quad=$ number of conidia do not germinate

The initiation of fungi was carried out on soybean plants aged 5 days using the seed immersion method and soil wetting with a density of B. bassiana 1 × 108 conidia / mL. Direct pathogenicity testing was carried out with density levels of 105, 106, 107, and 108 conidia / mL and observed for 7 days. Endophytic pathogenicity testing was carried out by infesting 20 crop aphids at age 20 dai and observing the growth aspects of plant height and number of leaf branches. Evaluation was carried out three times on soybean plants aged 5, 20 and 30 dai, respectively. This evaluation is carried out destructively and isolates samples of each part of the plant on PDA media which has been added with antibiotics.

\section{RESULT AND DISCUSSION}

\section{Evaluation of Beauveria bassiana as Endophytes in Soybean Plants}

Colonization of $B$. bassiana fungus on the stem of soybean plants reached $20 \%$. The mean percentage of ability of fungus $B$. bassiana to colonize soybean plants reached $6.67 \%$ of the total number of experimental units on stems. This may be caused by the symptoms of fungal colonization has not yet been visible. Previous study also demonstrated that several fungal endophytes may colonize in different part of plant including branches, stems, fruits, flowers, roots and leaves even without showing visible symptoms [4]

The low percentage of presence of $B$. bassiana fungus may also influenced by the readiness of plant metabolism in cope with inoculation time. Soybean plants used for inoculation of this fungus in soil wetting and seed soaking treatments were 5 days after planting.
Previous study also indicated that successful inoculation of several plants was carried out at the age of plants around 12, 14, 30, and 35 days $[5,6,7,8]$

Table 1. Percentage of colonization in parts of soybean plants at 30 dai

\begin{tabular}{lllll}
\hline \multirow{2}{*}{ Treatment } & \multicolumn{3}{c}{ Part of Plant (\%) } & Mean \\
\cline { 2 - 4 } & Root & Stem & Leaf & $(\%)$ \\
\hline Soaking seed with distilled water & 0,00 & 0,00 & 0,00 & 0,00 \\
Wetting soil with distilled water & 0,00 & 0,00 & 0,00 & 0,00 \\
Soaking seed with B. bassiana & 0,00 & 20,00 & 0,00 & 6,67 \\
Wetting soil with B. Bassiana & 0,00 & 0,00 & 0,00 & 0,00 \\
\hline
\end{tabular}

\section{Identification of Fungus Beauveria bassiana}

Macroscopic observations showed that the color of the colony is white, the edges are white and have a white base on the bottom. The surface of the convex colonies with the center is thicker than the edges and the surface texture is rather rough. The type of distribution of colonies is centered or concentric and round in shape. Microscopic observations showed that hyphae had hyaline and hyaline colors. Hyphae has a width of $1.48 \mu \mathrm{m}$ and a length of $10.26 \mu \mathrm{m}$. Conidiofor grows in a zig-zag pattern, has hyaline color, and has no branches. Konidia has a size of $2.68 \times 2.63$ $\mu \mathrm{m}$.
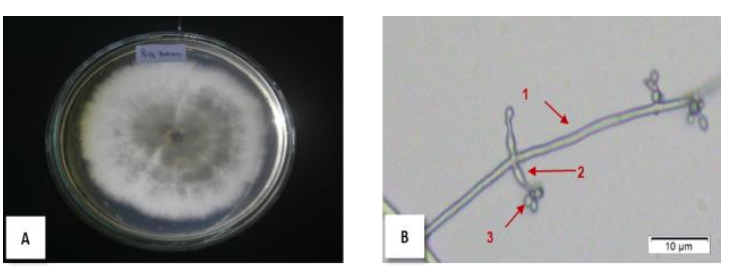

Figure 1. Macroscopic and microscopic morphology of $B$. bassiana fungus

The conidia density of $B$. bassiana fungi was $1.6 \times 10^{5}$ conidia / mL. Viability of conidia after 24 hours of incubation was $87.4 \%$. The evaluation of conidia viability was found to have decreased from the initial viability of the initiated $B$. bassiana fungus by $95 \%$.

\section{Effect of Beauveria bassiana Fungus Initiation on Plant Growth}

Symbiotic interactions between plants and insect pathogenic fungi result in increased plant growth. This increase occurs due to the reciprocal relationship between insect pathogenic fungi that provide nitrogen and plants that provide nutrients in the form of carbon from photosynthesis $[9,10]$. Other research also demonstrated that the growth of sun flower plant were greatly increased after treated with Penicillium citrinum, but not significant after treated with Aspergillus terreus 
[11]. This may suggest that the ability and of endophytic fungi to enhance the growth of host plant is likely depend on the compatibility of endophytic fungus and host plant. Our result showed there was no significant different on the growth of soybean plant between treated and untreated plant with endophytic fungi, B. bassiana. This may be caused by $\mathrm{B}$. bassiana may not have high compatibility with soybean plant thus could not increase the growth of plant significantly. However, further research still need to be conducted.

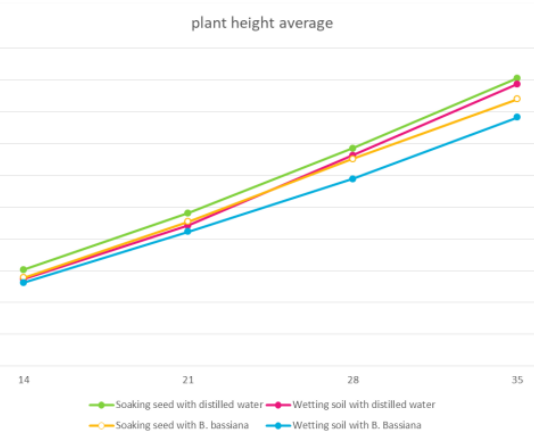

Figure 2. The mean height of soybean plants

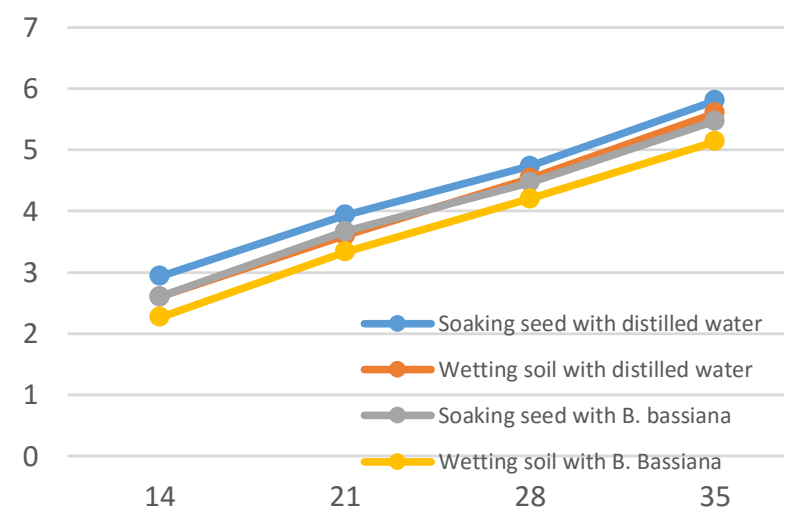

Figure 3. The mean number of branches of leaves of soybean plants

Other research also demonstrated that the Pathogenicity Test Results of Fungus Beauveria bassiana The concentration of fungus $B$. bassiana $10^{5}$ conidia / $\mathrm{mL}$ concentration resulted in the death of $A$. glycine aphids by $13.95-45.96 \%$ on the third day until the seventh day of observation. The concentration concentration of $B$. bassiana $10^{6}$ konidia / $\mathrm{mL}$ fungi resulted in the death of $A$. glycine aphids by $19.31-53.83 \%$ on the third day until the seventh day of observation. The concentration treatment of the density of fungi $B$. bassiana $10^{7}$ and $10^{8}$ conidia / $\mathrm{mL}$ resulted in death in sequential order of $2.1-53.07 \%$ and 3.71 - $60.31 \%$ on the second day until the seventh day of observation. A. glycine aphids also have a niche tendency at the end of meristem tissue from plants that have a greater nitrogen source. Localization of the $B$. bassiana fungus at the end of the meristem or the end of the plant has a lower density value than the rootstock and plant roots [12].

Table 2. Mortality of aphids for 7 days of observation (\%)

\begin{tabular}{cccccccc}
\hline Concentration & \multicolumn{7}{c}{ \% Mortality in Observation } \\
\cline { 2 - 8 } (conidia/mL) & 1 & 2 & 3 & 4 & 5 & 6 & 7 \\
\hline $10^{5}$ & $0,71^{\mathrm{a}}$ & $0,71^{\mathrm{a}}$ & $13,95^{\mathrm{a}}$ & $26,40^{\mathrm{a}}$ & $34,19^{\mathrm{a}}$ & $40,57^{\mathrm{a}}$ & $45,96^{\mathrm{a}}$ \\
$10^{\mathrm{b}}$ & $0,71^{\mathrm{a}}$ & $0,71^{\mathrm{a}}$ & $19,31^{\mathrm{a}}$ & $29,04^{\mathrm{a}}$ & $37,22^{\mathrm{a}}$ & $44,92^{\mathrm{a}}$ & $53,83^{\mathrm{a}}$ \\
$10^{7}$ & $0,71^{\mathrm{a}}$ & $2,1^{\mathrm{b}}$ & $22,79^{\mathrm{a}}$ & $34,15^{\mathrm{a}}$ & $42,04^{\mathrm{a}}$ & $47,97^{\mathrm{a}}$ & $53,07^{\mathrm{a}}$ \\
$10^{8}$ & $0,71^{\mathrm{a}}$ & $3,71^{\mathrm{b}}$ & $27,09^{\mathrm{a}}$ & $40,00^{\mathrm{a}}$ & $49,19^{\mathrm{a}}$ & $55,31^{\mathrm{a}}$ & $60,31^{\mathrm{a}}$ \\
\hline
\end{tabular}

Further research is needed on the level and concentration volume of insect pathogens given, abiotic factors such as temperature and $\mathrm{pH}$ levels, stability of insect pathogenic fungi in plant tissues, and interactions between plants, insect pathogenic fungi and insect pests or natural enemies. Further research is also on the biology of pests that can survive after the application of endophytic insect fungi, in addition, the detection of the distribution of insect pathogenic fungi in plant tissues using the sequencing method.

\section{CONCLUSION}

Colonization of B. bassiana fungus may visibly formed in stem, but not in other part of soyben plant. However, compatibility between fungal endophytes and the host plant may plays role in the successfulness of endophytic fungus in enhancing the growth as well as its role in reducing the major pest in its host, in this case is Aphid glycine in soybean plant. Further research still need to be conducted regarding factors influence the compatibility of fungal endophytes and the host plant.

\section{ACKNOWLEDGMENTS}

This research was supported by Hibah Peneliti Pemula Program Universitas Brawijaya with the contract number 1352 year of 2018.

\section{REFERENCES}

[1]. Indonesian National Statistic, 2016

[2]. Tilmon, K. J., E. W. Hodgson, M. E. O'Neal, dan D. W. Ragsdale., 2011. Biology of the Soybean Aphid, Aphis glycines (Hemiptera : Aphididae) in the United States. Journal of Integrated Pest Management 2 (2): 1 - 7.

[3]. Akutse, K.S., N.K. Maniania, K.K.M. Fiaboe, J. Van Den Berg, S. Ekesi. 2013. Endophytic Colonization of Vicia faba and Phaseolus vulgaris (Fabaceae) by Fungal Pathogens and 
Their Effects on The Lifehistory Parameters of Liriomyza huidobrensis (Diptera: Agromyzidae). Fungal Ecology 6 (4): 293 301.

[4]. Saikkonen K., Lehtonen P., Helander M., Koricheva J., Faeth S. H. (2006). Model systems in ecology: dissecting the endophyte-grass literature. Trends Plant Sci. 11 428-433.

[5]. Gurulingappa, P., P. A. McGee, G. A. Sword. 2011. Endophytic Lecanicillium lecanii and Beauveria bassiana Reduce the Survival and Fecundity of Aphis gossypii Following Contact with Conidia and Metabolites. Crop Protection 30 (3): $349-353$.

[6]. Parsa, S., V. Ortiz, dan F.E. Vega. 2013. Establishing Fungal Entomopathogens as Endophytes: Towards Endophytic Biological Control. Journal of Visualized Experiments 74: $1-5$.

[7]. Mantzoukas, S., C. Chondrogiannis, dan G. Grammatikopoulos. 2015. Effects of Three Endophytoc Entomopathogens on Sweet Sorgum and on The Larvae of The Stalk Borer Sesamia nonagrioides. Entomologia Experimentalis et Applicata 154 (1): 78 - 87.

[8]. Qayyum, M. A., W. Wakil, M. J. Arif, S. T. Sahi, C. A. Dunlap. 2015. Infection of Helicoverpa armigera by Endophytic Beauveria bassiana Colonizing Tomato Plants. Biological Control 90: $200-207$.

[9]. Behie, S.W., P.M. Zelisko, dan M.J. Bidochka. 2012. Endophytic Insect - Parasitic Fungi Translocate Nitrogen Directly from Insect to Plants. Science 336 (6088): 1576 - 1577

[10]. Behie, S.W., C.C. Moreira, I. Sementchoukova, L. Barelli, P.M. Zelisko, dan M.J. Bidochka. 2017. Carbon Translocation from a Plant to an Insect - Pathogenic Endophytic Fungus. Nature Communications 8 (14245): 1 - 5.

[11]. Waqas, M, Khan AL., Hamayun M, Shahzad R, Kang SM, Kim JG and Lee IJ. 2015. Endophytic fungi promote plant growth and mitigate the adverse effects of stem rot: an example of Penicillium citrinum and Aspergillus terreus

[12]. Behie, S.W., S.J. Jones, dan M.J. Bidochka. 2015. Plant Tissue Localization of The Endophytic Insect Pathogenic Fungi Metarhizium and Beauveria. Fungal Ecology 13: $112-119$ 